Motivation and Emotion, Vol. 30, No. 1, March 2006 (@ 2006)

DOI: $10.1007 / \mathrm{s} 11031-006-9000-6$

\title{
A Taxonomy of Anger-Related Behaviors in Young Adults
}

\author{
Hermina Van Coillie ${ }^{1,2}$ and Iven Van Mechelen ${ }^{1}$ \\ Published online: 25 July 2006
}

In 2 studies, we investigated the occurrence of anger-related behaviors and their relationship to emotional, performance-related, and situational variables. In the first study, we constructed a comprehensive taxonomy of behaviors associated with anger, and we examined the occurrence of the resulting behavior categories as a function of several independent variables. A total of 8 distinct behavior categories were identified, 3 aggressive and 5 nonaggressive. Our results also demonstrated that fight (including both verbal and physical aggression) and flight behaviors occurred most frequently. Physical aggression, however, occurred most frequently in an inhibited form, in response to the emotion of anger (as compared to the emotion of irritation), and when the anger was intense. A second study was conducted to replicate and extend the findings of Study 1. The results suggest that the taxonomy, as derived in Study 1, is comprehensive and allows for a reliable categorization. Moreover, it appeared that fight and flight behaviors occurred most frequently if the target at whom one is angry was present.

KEY WORDS: anger; behavior taxonomy; anger-related behaviors; intensity of emotion; coping; behavioral inhibition; aggression.

Anger is an emotion that can be considered as prototypical, and that people experience frequently (e.g., Averill, 1982). Furthermore, several authors have underscored the link between anger and behaviors (e.g., Frijda, Kuipers, \& ter Schure, 1989) leading to questions about the specific behaviors involved in such links. Intuitively, the behavior that seems most likely to occur as a result of anger is aggression (e.g., Berkowitz, 1990). Nonetheless, numerous behaviors beside aggression need to be considered (Averill, 1982; Linden et al., 2003).

A few studies have tried to make up comprehensive maps of behaviors associated with anger, on the basis of a free-listing task (e.g., Fitness \& Fletcher, 1993).

${ }^{1}$ Department of Psychology, University of Leuven, Tiensestraat 102, 3000, Leuven, Belgium.

${ }^{2}$ To whom correspondence should be addressed at e-mail: hermina.vancoillie@psy.kuleuven.be. 
In terms of content, these free-listing studies illustrate the different ways in which a person may respond while angry. Unfortunately, however, most free-listing studies suffer from important methodological limitations. In many cases, the way in which the behavioral categories were created was not described clearly. Moreover, some behavior categories were not constructed on the basis of any data, instead, they were constructed by the researchers using their own preexisting categories. Therefore, although valuable efforts have been made to construct taxonomies, a completely satisfactory result is not presently available.

In this paper, we describe the results of two studies that were intended to provide a comprehensive taxonomy of anger-related behaviors. For this purpose, participants performed a free-listing task in which they generated lists of all the anger-related behaviors they could think of. The instructions in this task further varied across four factors, namely the nature (anger vs. irritation) and intensity of the emotion (high vs. low), whether the behavior was used to cope with the emotion or not (coping vs. no explicit coping), and the performance status (executed vs. inhibited vs. other) of the anger-related behaviors. These four variables were selected on the basis of previous research on emotion-related behavior, to create a comprehensive behavior taxonomy, and to examine how the frequencies of the behaviors vary across them.

Regarding the nature of the emotion, few studies have investigated whether different anger-related emotions elicit different action tendencies or behaviors. Exceptions include studies by Frijda et al. (1989) and Averill (1982), both of whom found differences in behavior and action readiness patterns associated with anger and irritation. In the present study, we examined the extent to which the action tendencies and behaviors associated with anger and irritation differed.

Despite the fact that "the intensity of an emotion is one of its most noticeable aspects" (Sonnemans \& Frijda, 1994, p. 329), little research has focused on the relationship between emotional intensity and action tendencies or behaviors. Moreover, with regard to anger, results on the relationship between the two are somewhat mixed: Some research has found a positive relationship (e.g., Deffenbacher, Lynch, Oetting, \& Yingling, 2001), whereas other research has found no relationship (e.g., Averill, 1982). The present study was intended to clarify this issue.

Coping has been conceptualized as the cognitive and behavioral efforts people use to manage specific demands that are implied by a stressful situation (Folkman, 1984). Assuming that anger is stressful, many studies have investigated coping in the context of anger (e.g., Herrald \& Tomaka, 2002), unfortunately, however, without conclusive results on which behaviors people preferentially use to cope with anger. To clarify this issue, we asked half of the participants in our study what behaviors they had used to cope with their anger.

Finally, especially for anger, what people do, should be distinguished from what they want to do, but do not do, as one may not always do what one wants. This relates to the concept of behavioral inhibition. Some studies have found 
that aggressive behaviors are inhibited more often than other behaviors, yet a meaningful degree of inhibition has also been found for some nonaggressive behaviors (Averill, 1982; Kassinove, Sukhodolsky, Tsytsarev, \& Solovyova, 1997). To investigate this further, in our study, the performance status of a behavior was considered in three mutually exclusive forms: a do-form, pertaining to behaviors that participants had exhibited, a want-form, pertaining to behaviors participants wanted to do, but did not do, and a possible-form, pertaining to behaviors for which participants did not experience an action tendency, but that they nevertheless associated with anger. This allowed us to examine which types of responses are executed and inhibited and whether the execution and inhibition depend on the nature and/or the intensity of the emotion.

\section{OVERVIEW}

Two empirical studies are reported in this paper. In Study 1, we constructed an exhaustive anger-related behavior taxonomy; subsequently, we examined the relative frequencies of the behavior categories and their relationship with the emotion- and performance-related independent variables. Study 2 was designed to confirm the comprehensiveness and reliability of the behavior taxonomy of Study 1 and to replicate and sharpen some of its frequency-related results. In addition, we also investigated the influences of gender and a situational variable on the occurrence of the different behavior categories.

\section{STUDY 1}

\section{Step 1: Behavior Generation Task}

\section{Method}

Participants. Participants were 178 first-year psychology students of the University of Leuven (34 men and 144 women), with a mean age of 18.25 years $(S D=1.34)$. Participation in the study was in partial fulfillment of a study course requirement.

Materials and Procedure. Participants were tested in a classroom setting. Each participant was randomly assigned to complete one of eight different questionnaires, which were constructed by crossing three variables: the nature of the emotion (anger vs. irritation), the intensity of the emotion (high vs. low) and the coping of the behavior (no explicit coping vs. coping). The performance status of the behavior (do vs. want vs. possible) was manipulated as a within-participant variable.

Instructions to generate the behaviors varied across the eight questionnaires. For instance, participants who received the high intensity-anger-no explicit coping 
questionnaire received the following three questions: (a) "Which reactions have you done when you were very angry" (respectively, "wanted to do, but have you never done," and "do you think are possible but have you never wanted to do, nor done"). Instructions for the other questionnaires were similar, with variations for the nature (anger vs. irritation) and intensity of the emotion (very vs. a bit), and coping of the behavior (done vs. done to cope with your emotion). After each question, space was given to note up to 10 responses.

\section{Results}

After the deletion of invalid responses, 1,315 behaviors were obtained $(M=$ $7.51, S D=3.26$ ). The obtained responses were reduced by means of six reduction rules $^{3}$ to 679 different behavior groups, containing between 1 (e.g., biting) and 65 (screaming) behaviors.

\section{Step 2: Construction of Taxonomy}

\section{Step 2.1. Free Similarity-Sorting Task: Method}

Participants. Participants were 51 students of the University of Leuven (17 men and 34 women). None of them had participated in the behavior generation task. They were tested individually and received five Euros. Their mean age was 21.0 years $(S D=3.4)$.

Materials. To make up a manageable list of behaviors for this task (Coxon, 1999), we randomly selected three participants from each condition out of Step 1. Together, those 24 participants generated 167 behaviors, which, after applying the reduction rules described earlier, left 120 behavior groups. From each group, we selected the behavior with the highest frequency. The 120 selected behaviors were typed on small index cards.

Procedure. Participants were told they would receive a set of 120 index cards (each deck in a different random order) with each card containing a behavior. They had to sort the cards in a number of groups, so that behaviors with a similar meaning were placed in the same group. On average, participants generated 8.13 different behavior groups $(S D=3.37)$.

\footnotetext{
${ }^{3}$ The following reduction rules were used: (a) responses that differed only in the order of the words were put together; (b) singular and plural items were joined; (c) responses that differed only in verbs such as "to be," "to become" or "to do" were grouped together; (d) responses that differed only syntactically (verb, noun or adjective) were grouped together; (e) responses that differed only with respect to an article, a preposition, or a possessive word were grouped together; (f) and a few specific rules were used (e.g., yourself $=$ myself; self $=$ auto).
} 


\section{Step 2.2: Hierarchical cluster analysis}

Method. For each participant, a $120 \times 120$ behavior by behavior symmetric co-occurrence matrix $C_{k}$ was constructed, with " 1 " in a cell indicating that the two behaviors were placed in the same category and " 0 " indicating that they were not. These matrices were added across the 51 participants to obtain a single similarity matrix $C$. This $C$ matrix was then transformed into a dissimilarity matrix $D$, by subtracting each cell entry from 51 . The $D$ matrix was used as input for an average linkage hierarchical cluster analysis.

Three statistics were used to decide how many clusters to retain, namely the $C$ index, the Calinski and Harabasz index, and the Pseudo $t^{2}$ index (Milligan \& Cooper, 1985). On the basis of these three statistics, we chose a solution with eight clusters, which is displayed in Fig. 1.

Results. Figure 1 clearly shows that the obtained taxonomy encompasses two main clusters, one with aggressive and one with nonaggressive behaviors. Within the former, a further distinction can be made between externally and internally directed aggression. Externally directed aggression can be physical or verbal and varies between very mild and very extreme forms. The third aggressive cluster, which we labeled self-aggression, because it contained internally directed aggression, included both self-mutilation and behaviors such as bottling up the anger.

With respect to the nonaggressive cluster, a similar distinction between internally and externally directed behaviors could be made. Externally directed

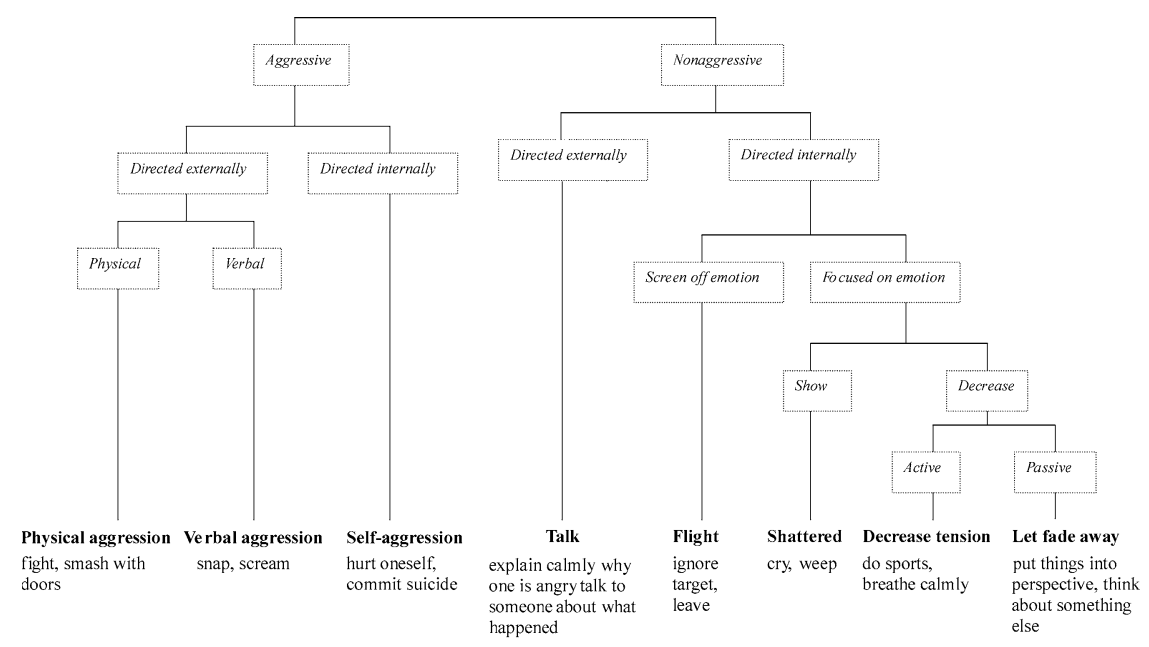

Fig. 1. Results of average linkage hierarchical cluster analysis of 120 behaviors up to solution with eight clusters, including some examples from each category. 
nonaggressive behaviors constituted a cluster that we labeled the talk category, because it contained behaviors that imply talking in a nonaggressive way, either to the target of the anger or to other people. Within the internal cluster, a category could be distinguished that contained behaviors in which one turns away from the target or the situation, and we labeled this the flight category. Next, there was a cluster that encompassed behaviors in which the focus is on emotion. This cluster was further divided into a cluster that included behaviors that show that one has been negatively affected by the episode-we called it the shattered category-and another that referred to a decrease in emotions. This decrease cluster was further divided into an active and passive cluster. The active cluster contained behaviors in which one attempts to work off tension in a nondestructive way, or tries to relax oneself. The passive cluster contained behaviors in which one attempts to make an emotion fade away.

Discussion. The results suggest that a broad scope of behaviors is associated with anger, several of them already being reported in previous research. Our results further reconcile two important claims that have been made in the anger domain. On one hand, there is the assertion that aggression is closely related to anger and irritation (e.g., Berkowitz, 1990); our findings are in line with this assertion as three of the eight behavior categories were found to be aggressive. On the other hand, it has been stated that a broad range of nonaggressive behaviors is related to anger as well (e.g., Linden et al., 2003), which is also supported by our results.

Finally, a basic distinction within both aggressive and nonaggressive behaviors was whether behaviors were internally or externally directed. This distinction is important in many domains, including personality and social psychology (Rotter, 1971), and clinical psychology (Krueger, 1999). In particular, with respect to anger expression, a well-known distinction is that between anger-in and anger-out (Spielberger, Krasner, \& Solomon, 1988). Anger-in generally refers to internalizing the anger, whereas anger-out refers to its overt display. In terms of the present taxonomy, the anger-out group seems to correspond to the cluster of externally directed aggressive behavior, whereas many anger-in behaviors are in our two clusters of internally directed behaviors (self-aggression and flight).

\section{Step 2.3. Coding task: method}

Participants. Three trained experts, all experienced psychologists, participated in the coding task. Their mean age was 27 years $(S D=2.6)$. None had participated in any of the previous tasks.

Materials. For this task, all 559 behavior groups collected in the first step that were not included in the free similarity-sorting task were used. If multiple behaviors had been grouped together, we systematically selected one term to represent the corresponding behavior group. 
Procedure. Participants received an extensive training. First, the content of the different behavior categories was explained to them. The same information was also provided in a written coding manual. ${ }^{4}$ Second, they were asked to classify the selected list of 120 behaviors into the eight categories. The instructions, the behaviors, and a description of the behavior categories were presented via a computer. The behaviors were in a randomized order that differed for each participant. Afterwards, participants received feedback on the correctness of their classification.

After the training, participants started with the computerized coding task, in which they were asked to assign all 559 behaviors (again being in a randomized order) to the eight behavior categories. An additional rest category was provided for behaviors that did not fit into any of the categories under study.

Results and Discussion. To measure the interrater agreement, we computed per pair of raters Cohen's (1960) kappa for the nine categories together. All kappa coefficients turned out to be very high $(.70, .71$, and .80$)$. Furthermore, only $1.3 \%$ of the behaviors were classified in the rest category. Taken together, these results suggest that our taxonomy was exhaustive and allowed for a reliable categorization.

\title{
Step 3: Relative Frequencies of the Behavior Categories and Their Relationship to Independent Behavior and Emotion Variables
}

\author{
Results
}

Relative Frequencies of the Behavior Categories. For each behavior category, we calculated the percent of participants who generated at least one behavior for that category (in any of the three performance categories). Figure 2 depicts the resulting proportions. Physical and verbal aggression were most frequently reported, followed by flight behaviors.

Relative Frequencies of the Behavior Categories as a Function of the Independent Variables. To examine relationships between the four emotion and behavior variables and the frequencies of behavior categories, first, we calculated for each category and for each level of each independent variable the total number of behaviors that were generated and divided this by the corresponding maximum possible frequency. The resulting proportions are listed in Table I. Next, stepwise logistic multiple regression analyses were performed separately for each behavior category across all participant-performance level combinations, with category occurrence being the dependent measure and the four independent variables as predictor variables. The final models included only effects that were significant $(p<.05)$ or that were subsumed under an interaction term in the model. These

\footnotetext{
${ }^{4}$ The complete coding manual is available upon request from the first author.
} 


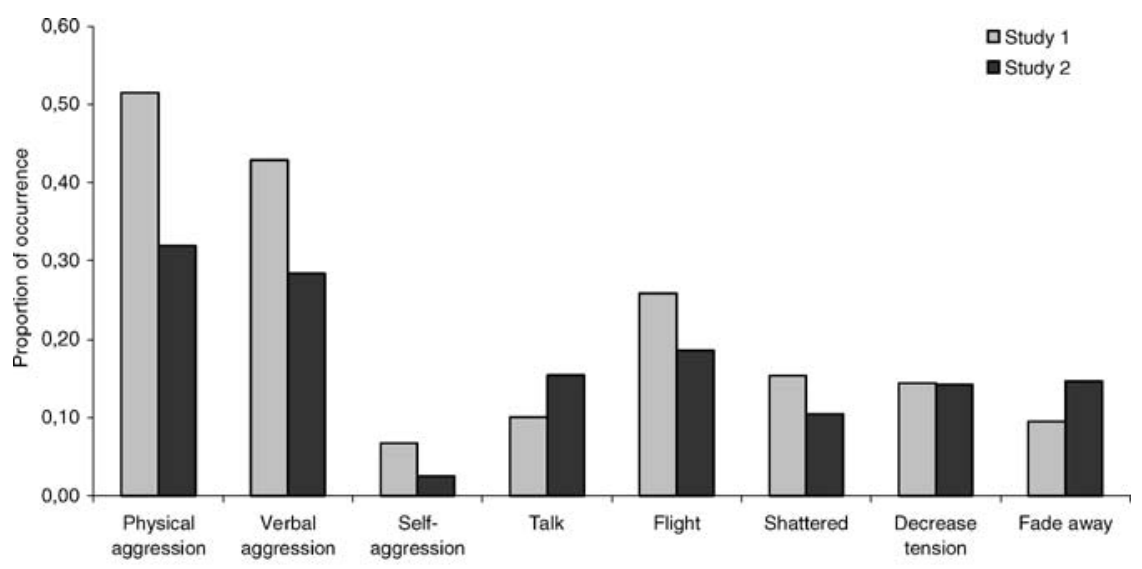

Behavior categories

Fig. 2. Proportion of occurrence for the eight behavior categories in Study 1 and Study 2.

results are summarized in Table II. ${ }^{5,6}$ Regarding the nature of the emotion, the difference between anger and irritation was most pronounced for physical aggression. This behavior category was reported more often in the anger than in the irritation conditions, $\chi^{2}(1, N=48)=17.70, p<.01$. Smaller differences in the opposite direction were found for behavior categories that implied the use of words, namely verbal aggression, $\chi^{2}(1, N=46)=5.63, p=.02$, and talk, $\chi^{2}(1, N=39)=6.09, p=.01$.

Regarding emotion intensity, differences occurred for physical aggression and let fade away. Physical aggression was reported more frequently in the high as compared to the low intensity condition, $\chi^{2}(1, N=48)=9.44, p<.01$, whereas the reverse was true for let fade away, $\chi^{2}(1, N=42)=7.42, p<.01$.

Concerning coping, there were main effects for talk, $\chi^{2}(1, N=39)=12.80$, $p<.01$, and decrease tension, $\chi^{2}(1, N=43)=20.19, p<.01$; both were higher in the coping condition. In contrast, verbal aggression $\chi^{2}(1, N=46)=12.16$, $p<.01$, and flight, $\chi^{2}(1, N=46)=10.41, p<.01$, were lower in the coping condition.

With regard to performance status, post hoc contrasts were computed, the results of which are displayed in columns 5-7 of Table I. For more than half of

\footnotetext{
${ }^{5}$ This number differed across proportions because it depended on the number of participants assigned to each of the experimental questionnaires.

${ }^{6}$ Our initial analyses contained a participant-specific random intercept, so as to take into account individual differences in the propensity to use each of the behavior categories. Inclusion of a random intercept appeared to yield a significant improvement in model fit for two of the eight behavior categories. However, because analyses with a random and with a fixed intercept yielded similar conclusions, we decided to select the most parsimonious model, namely the one without a random intercept.
} 
Table I. Proportion of Occurrence for the Eight Behavior Categories and for Each Level of the Four Independent Variables (study 1)

\begin{tabular}{|c|c|c|c|c|c|c|c|c|c|}
\hline \multirow[b]{3}{*}{ Behavior category } & \multirow{2}{*}{\multicolumn{2}{|c|}{ Nature }} & \multirow{2}{*}{\multicolumn{2}{|c|}{ Intensity }} & \multirow{2}{*}{\multicolumn{3}{|c|}{ Performance status }} & \multicolumn{2}{|c|}{ Instrumentality } \\
\hline & & & & & & & & No explicit & \\
\hline & Anger & Irritation & High & Low & Do & Want & Possible & coping & Coping \\
\hline Physical aggression & $.61_{\mathrm{a}}$ & $.43_{\mathrm{b}}$ & $.58 \mathrm{a}$ & $.44_{\mathrm{b}}$ & $.43_{\mathrm{a}}$ & $.57_{\mathrm{b}}$ & $.54_{\mathrm{ab}}$ & $.51_{\mathrm{a}}$ & $.52_{\mathrm{a}}$ \\
\hline Verbal aggression & $.38_{\mathrm{a}}$ & $.47_{b}$ & $.44_{\mathrm{a}}$ & $.42 \mathrm{a}$ & $.84 \mathrm{a}$ & $.27_{\mathrm{b}}$ & $.17_{\mathrm{b}}$ & $.49 \mathrm{a}$ & $.37_{\mathrm{b}}$ \\
\hline Self-aggression & $.06_{\mathrm{a}}$ & $.07 \mathrm{a}$ & $.08_{\mathrm{a}}$ & $.05_{\mathrm{a}}$ & $.07 \mathrm{ab}$ & $.03 \mathrm{a}$ & $.11_{\mathrm{b}}$ & $.05_{\mathrm{a}}$ & $.09_{\mathrm{a}}$ \\
\hline Talk & $.07 \mathrm{a}$ & $.13_{\mathrm{b}}$ & $.09 \mathrm{a}$ & $.11_{\mathrm{a}}$ & $.21_{\mathrm{a}}$ & $.08_{\mathrm{b}}$ & $.01_{\mathrm{c}}$ & $.06_{\mathrm{a}}$ & $.15_{\mathrm{b}}$ \\
\hline Flight & $.24_{a}$ & $.27 \mathrm{a}$ & $.25_{\mathrm{a}}$ & $.27 \mathrm{a}$ & $.58 \mathrm{a}$ & $.13_{\mathrm{b}}$ & $.06_{\mathrm{b}}$ & $.31_{\mathrm{a}}$ & $.21_{\mathrm{b}}$ \\
\hline Shattered & $.18 \mathrm{a}$ & $.13 \mathrm{a}$ & $.18 \mathrm{a}$ & $.13 \mathrm{a}$ & $.38 \mathrm{a}$ & $.02_{\mathrm{b}}$ & $.06_{\mathrm{b}}$ & $.16_{\mathrm{a}}$ & $.15_{\mathrm{a}}$ \\
\hline Decrease tension & $.13 \mathrm{a}$ & $.16_{\mathrm{a}}$ & $.14_{\mathrm{a}}$ & $.15_{\mathrm{a}}$ & $.33_{\mathrm{a}}$ & $.06_{b}$ & $.04_{\mathrm{b}}$ & $.08_{\mathrm{a}}$ & $.21_{\mathrm{b}}$ \\
\hline Let fade away & $.07 \mathrm{a}$ & $.12 \mathrm{a}$ & $.06_{a}$ & $.13_{\mathrm{b}}$ & $.17 \mathrm{a}$ & $.08_{\mathrm{b}}$ & $.03_{\mathrm{b}}$ & $.08_{\mathrm{a}}$ & $.11_{\mathrm{a}}$ \\
\hline
\end{tabular}

Note. For each independent variable separately, means in the same row that do not share subscripts differ at the familywise $\alpha$ level of .05; for performance status, contrasts were computed via Dunn's multiple comparison procedure.

the behavior categories, a significantly higher proportion of behaviors was located in the do-form. For physical aggression, the highest proportion occurred in the want-form, which is a direct indication for behavioral inhibition.

For physical aggression, the nature of the emotion was involved in an interaction with performance status, $\chi^{2}(1, N=48)=9.57, p<.01$. The interaction stems from the proportion of physical aggression to be much higher in the wantform of the anger condition as compared to all other cells, indicating a strong and inhibited urge in that case. For decrease tension, there was an interaction between instrumentality and performance status, $\chi^{2}(1, N=43)=5.43, p=.02$, with a

Table II. Summary of Logistic Regression Analyses with Regression Weights (Main Effects Only) for Emotion and Behavior Variables Predicting the Relative Frequencies of Occurrence of the Eight Behavior Categories (Study 1)

\begin{tabular}{|c|c|c|c|c|c|c|}
\hline \multirow[b]{2}{*}{ Criterion } & \multicolumn{6}{|c|}{ Regression weights } \\
\hline & Intercept & Nature & Intensity & $\begin{array}{l}\text { Performance } \\
\text { status } \\
\text { (do-form) }\end{array}$ & $\begin{array}{l}\text { Performance } \\
\text { status } \\
\text { (want-form) }\end{array}$ & Instrumentality \\
\hline $\begin{array}{l}\text { Physical } \\
\quad \text { aggression }\end{array}$ & -0.46 & $0.76^{* *}$ & $0.55^{* *}$ & $-0.48^{* *}$ & 0.09 & \\
\hline Verbal aggression & $-1.77^{* *}$ & $-0.54^{*}$ & & $3.39^{* *}$ & $0.58^{*}$ & $0.80^{* *}$ \\
\hline Self-aggression & $-2.13^{* *}$ & & & -0.50 & $-1.42^{*}$ & \\
\hline Talk & $-4.43^{* *}$ & $-0.80^{*}$ & & $3.97^{* *}$ & $2.83^{* *}$ & $-1.19^{* *}$ \\
\hline Flight & $-3.17^{* *}$ & & & $3.14^{* *}$ & $0.82^{*}$ & $0.78^{* *}$ \\
\hline Shattered & $-2.82^{* *}$ & & & $2.34^{* *}$ & -0.95 & \\
\hline Decrease tension & $-2.72^{* *}$ & & & $2.61^{* *}$ & 0.48 & $-0.41^{* *}$ \\
\hline Let fade away & $-3.17^{* *}$ & & $-0.85^{* *}$ & $2.01^{* *}$ & $1.17^{*}$ & \\
\hline
\end{tabular}


higher proportion of decrease tension behaviors being reported in the do-form of the instrumentality condition.

\section{Discussion}

Our results demonstrated that fight (i.e., physical and verbal aggression) and flight behaviors are most frequently reported. This links up with two major behavioral alternatives that, since their introduction by Cannon (1932), have primarily been investigated as basic coping responses within the stress domain. Our results are thus consistent with our initial assumption that anger-provoking situations are similar to stressful events, and that coping responses can therefore be conceived as relevant for anger too.

Although we found that the behaviors associated with anger and irritation are quite similar, the two emotions also differ, primarily in terms of externally directed behaviors. In particular, physical aggression was more frequently reported in conjunction with anger than with irritation, whereas significant but smaller differences in the reverse direction were found for the two verbal behavior categories. Apparently, anger is primarily associated with more and irritation with less strong responses.

With regard to emotional intensity, we found that for both anger and irritation, high emotional intensity was associated with more physical aggression (see also Deffenbacher et al., 2001) and less with let fade away. One way to think of these results is that these behavior categories represent opposite positions on a dimension of vigor, with the behaviors of the most vigorous behavior category, physical aggression, being more associated with a high intense emotion and with the reverse being true for the least vigorous behavior category, let fade away. These findings are consistent with theorizing and research by Sonnemans and Frijda (1994), who found a positive relationship between subjective emotional intensity and the vigor of the associated action tendency and behavior.

In terms of overall frequency, fight and flight responses occurred most frequently, although this finding has to be qualified by performance status. For the executed behaviors, the peak with regard to fight behaviors primarily pertained to verbal aggression, physical aggression showing up in inhibited and merely possible form, rather. Possibly, the latter may be due to the fact that physical aggression receives a lot of attention in media sources. All in all, we seem to be able to reconcile two, at first sight paradoxical, earlier findings, namely that anger is strongly associated with physical aggression (e.g., Berkowitz, 1990) and that physical aggression is not observed all that frequently within an anger context (e.g., Averill, 1982).

With respect to coping, although all behavior categories are used to cope with the emotions under study, talk and decrease tension were used more, and verbal aggression and flight less frequently as coping behaviors. To explain these findings, 
one may appeal to the fact that both the decrease tension and talk categories (unlike verbal aggression and flight) have been found to be associated with a variety of positive emotional consequences (e.g., Pennebaker, Zech, \& Rimé, 2001).

It must finally be noted that the study discussed previously suffers from some limitations. First, our coping conditions were not mutually exclusive in that coping behaviors could also be reported in the "no explicit coping condition." Second, in the coping literature, two coping strategies have been distinguished, namely emotion- and problem-focused coping (e.g., Folkman, 1984) whereas in our study, we focused only on the first type of strategy. Third, our sample includes more women than men. Finally, despite the fact that we recognize situational influences on the occurrence of anger-related behaviors, we did not include any situational variable in our study.

\section{STUDY 2}

The purpose of Study 2 was to check the comprehensiveness and reliability of our behavior taxonomy and to replicate and sharpen some of the frequencyrelated results. Also, we wanted to extend the findings of Study 1 by investigating the influences of both gender and a situational variable on the occurrence of the different behavior categories.

With regard to situational variables, several studies have found that the presence of other persons affects the execution of anger-related behaviors (e.g., Diener, 1976). However, in these studies, the primary focus was on the presence of bystanders, the target of the anger always being present. Nevertheless, for the execution of some behaviors, the target's presence may be a prerequisite, whereas for other behaviors, its absence may be preferable. Therefore, in Study 2 , we investigated the influence of the presence of the target of the anger on the occurrence of our eight anger-related behaviors.

With respect to gender, the dominant view is that men are generally more violent than women (e.g., Linden et al., 2003); however, several studies suggest that gender differences tend to be small (e.g., Averill, 1982) or go in the reverse direction (e.g., Suter, Byrne, Byrne, Howells, \& Day, 2002). Also, inconsistent results have been reported regarding most nonaggressive anger-related behaviors. In fact, the only robust finding seems to be that when angry, women tend to express their feelings more than men do, for instance by crying (Timmers, Fischer, \& Manstead, 1998). By including an equal amount of female and male participants, we intended to increase the generalizability of our findings and to examine gender differences more accurately.

In Study 2, we also simplified the design of Study 1 and remedied some of its limitations. In particular, we restricted ourselves to executed and inhibited behaviors and we focused on only instances in which participants were "very angry". To deal with the problem of the nonexhaustiveness of the coping 
conditions, we introduced a condition in which any form of coping was excluded, an emotion-focused, and a problem-focused coping condition. We further manipulated coping as a within-participant variable, to increase participants" awareness of the distinctions between the different types of coping.

\section{Step 1: Behavior Generation Task}

\section{Method}

Participants. Participants were 84 university students (42 men and 42 women) enrolled in the first year of a psychology educational program. None of them had participated in Study 1. Their mean age was 18.25 years $(S D=$ 0.87). Participation was in partial fulfillment of course credit.

Materials and Procedure. The design of the Study 2 was modeled closely on that of Study 1. Two different questionnaires were constructed, one with the target of the anger present and the other with the target absent. Equal numbers of men and women were assigned to both conditions. Participants had to answer six questions that represented the combination of coping (emotion-focused vs. problem-focused vs. no coping) and performance status (do vs. want).

The first three questions of the target-present version of the questionnaire, representing the do-form of performance status and varying for coping, read as follows: Which behaviors have you already done when you were very angry with someone else, and the person at whom you were very angry was present, with a primary aim to cope with your feeling of anger (respectively with the situation that made you angry), and which other behaviors have you already done in that case. The three questions representing the want-form were the same, except for the replacement of "done" by "wanted to do but have you never done". For the target-absent version of the questionnaire, "present" was replaced by "absent". After each question, space was given to note up to 10 responses.

\section{Results}

After the omission of invalid responses, 955 behaviors were obtained $(M=$ $11.37, S D=5.41$ ). The responses were reduced to 589 behavior groups by means of the reduction rules.

\section{Step 2: Coding task}

\section{Method}

Participants. The same three experts of Study 1 coded the responses.

Materials and Procedure. The 589 behavior groups collected in the previous step were used. As in Study 1, we selected one term to represent each behavior 
group. The experts received the same instructions and coding manual as in Study 1 (Step 2.3) and sorted all 589 behaviors into one of the eight behavior categories or in the rest category.

\title{
Results and Discussion
}

To measure interrater agreement, we computed per pair of raters Cohen's (1960) kappa for the nine categories together. All kappa coefficients turned out to be very high $(.84, .86$, and .90$)$. Furthermore, only $1.9 \%$ of the behaviors was classified in the rest category. Taken together, these results suggest that our taxonomy was comprehensive and allowed for a reliable categorization.

\section{Step 3: Relative Frequencies of the Behavior Categories and Their Relationship to Independent Variables}

\author{
Results
}

Similar to Study 1, we calculated, for each behavior category, the proportion of respondents who described at least one behavior from that category in each of the participant-performance-instrumentality level combinations. Figure 2 depicts the resulting proportions. From this figure, it appears that, as in Study 1, physical and verbal aggression are most frequently reported. ${ }^{7}$

To inspect in more detail the relationship between the independent variables and the proportions of the eight behavior categories, we first calculated for each category and for each level of the independent variables the proportion of behaviors that was generated. The results are listed in Table III. Next, stepwise logistic multiple regression analyses were performed separately for each behavior category across all participant-performance-instrumentality level combinations, with category occurrence as dependent measure and the four independent variables as predictor variables. Table IV displays the summary of the results.

Concerning performance status, it appears that for six behavior categories, a significantly higher proportion of behaviors occurred in the do-form as compared to the want-form. This was the case for verbal aggression, $\chi^{2}(1, N=48)=9.53$, $p<.01$; talk, $\chi^{2}(1, N=40)=35.72, p<.01$; flight, $\chi^{2}(1, N=46)=1.43$, $p<.01$; shattered, $\chi^{2}(1, N=37)=3.67, p<.01$; decrease tension, $\chi^{2}(1, N=$ $38)=2.87, p<.01$; and let fade away, $\chi^{2}(1, N=40)=1.99 ; p<.01$. Apart from physical aggression, these results replicate those of Study 1.

With regard to coping, contrast calculations were performed, the results of which are displayed in columns 3-5 of Table III. As can be seen in this table,

\footnotetext{
${ }^{7}$ The total number of participant-performance-instrumentality combinations equals 504 (i.e., $84 \times 6$ ) because all 84 participants had to answer six questions.
} 
Table III. Proportion of Occurrence for the Eight Behavior Categories and for Each Level of the Four Independent Variables (Study 2)

\begin{tabular}{|c|c|c|c|c|c|c|c|c|c|}
\hline \multirow[b]{2}{*}{ Behavior category } & \multicolumn{2}{|c|}{$\begin{array}{c}\text { Performance } \\
\text { status }\end{array}$} & \multicolumn{3}{|c|}{ Instrumentality } & \multicolumn{2}{|c|}{$\begin{array}{c}\text { Presence of the } \\
\text { target }\end{array}$} & \multicolumn{2}{|c|}{ Gender } \\
\hline & Do & Want & $\mathrm{EFC}$ & PFC & $\mathrm{NC}$ & Present & Absent & Men & Women \\
\hline Physical aggression & $.47_{\mathrm{a}}$ & $.49 \mathrm{a}$ & $.61_{\mathrm{a}}$ & $.11_{\mathrm{b}}$ & $.24_{\mathrm{c}}$ & $.34_{\mathrm{a}}$ & $.30 \mathrm{a}$ & $.34_{\mathrm{a}}$ & $.30 \mathrm{a}$ \\
\hline Verbal aggression & $.61_{\mathrm{a}}$ & $.24_{\mathrm{b}}$ & $.50_{\mathrm{a}}$ & $.21_{\mathrm{b}}$ & $.14_{\mathrm{b}}$ & $.33_{\mathrm{a}}$ & $.24_{\mathrm{b}}$ & $.29 \mathrm{a}$ & $.27_{\mathrm{a}}$ \\
\hline Self-aggression & $.05_{\mathrm{a}}$ & $.022_{\mathrm{a}}$ & $.05_{\mathrm{a}}$ & $.02_{\mathrm{b}}$ & $.01_{\mathrm{b}}$ & $.03_{\mathrm{a}}$ & $.022_{\mathrm{a}}$ & $.03_{\mathrm{a}}$ & $.022_{\mathrm{a}}$ \\
\hline Talk & $.38_{\mathrm{a}}$ & $.08_{\mathrm{b}}$ & $.14_{\mathrm{a}}$ & $.29 \mathrm{~b}$ & $.04_{\mathrm{c}}$ & $.11_{\mathrm{a}}$ & $.20_{\mathrm{b}}$ & $.15_{\mathrm{a}}$ & $.16_{\mathrm{a}}$ \\
\hline Flight & $.42_{\mathrm{a}}$ & $.14_{b}$ & $.29 \mathrm{a}$ & $.19_{\mathrm{b}}$ & $.08_{\mathrm{c}}$ & $.26_{\mathrm{a}}$ & $.11_{\mathrm{b}}$ & $.18_{\mathrm{a}}$ & $.19_{\mathrm{a}}$ \\
\hline Shattered & $.30_{\mathrm{a}}$ & $.01_{\mathrm{b}}$ & $.20_{\mathrm{a}}$ & $.07 \mathrm{~b}$ & $.04_{b}$ & $.09 \mathrm{a}$ & $.12_{\mathrm{a}}$ & $.07 \mathrm{a}$ & $.14_{\mathrm{b}}$ \\
\hline Decrease tension & $.39 \mathrm{a}$ & $.04_{\mathrm{b}}$ & $.24_{\mathrm{a}}$ & $.13_{\mathrm{b}}$ & $.07_{\mathrm{b}}$ & $.09 \mathrm{a}$ & $.19_{\mathrm{b}}$ & $.14_{\mathrm{a}}$ & $.14_{\mathrm{a}}$ \\
\hline Let fade away & $.36_{a}$ & $.08_{\mathrm{b}}$ & $.13_{\mathrm{a}}$ & $.30_{\mathrm{b}}$ & $.01_{\mathrm{c}}$ & $.12_{\mathrm{a}}$ & $.17_{\mathrm{a}}$ & $.16_{a}$ & $.13_{\mathrm{a}}$ \\
\hline
\end{tabular}

Note. For each independent variable separately, means in the same row that do not share subscripts differ at the familywise $\alpha$ level of .05, for instrumentality, contrasts were computed via Dunn's multiple comparison procedure. EFC: emotion-focused coping; PFC: problem-focused coping; NC: no coping.

most behavior categories were used in both the coping and no coping conditions. In addition, proportions in the latter were lower. For six behavior categories, the largest proportion of behaviors occurred in the emotion-focused coping conditions, whereas for talk and let fade away, a higher proportion occurred in the problemfocused coping conditions.

Concerning presence/absence of the target of anger, verbal aggression, $\chi^{2}(1$, $N=48)=6.61, p=.01$, and flight, $\chi^{2}(1, N=46)=20.02, p<.01$, were more frequently reported when the target was present; for talk, $\chi^{2}(1, N=40)=$ $8.80, p<.01$, and decrease tension, $\chi^{2}(1, N=38)=12.83, p<.01$, the reverse occurred, the former suggesting that social sharing behaviors dominate the content of the talk category.

Gender differences were found for the shattered category only. Women reported being shattered more frequently than men, $\chi^{2}(1, N=37)=9.05, p<$ .01 .

For verbal aggression, coping was involved in an interaction with performance status, $\chi^{2}(1, N=48)=8.87, p=.01$, verbal aggression being executed more if participants intended to cope with the emotion. For flight, presence of target was involved in an interaction with performance status, $\chi^{2}(1, N=46)=$ $4.55, p=.03$, flight behaviors occurring more if the target was present.

\section{Discussion}

The results of Study 2 largely replicated and extended those of Study 1. First, the new set of anger-related behaviors could be reliably and almost completely categorized in the taxonomy, showing that our taxonomy is fairly comprehensive and allows for a replicable categorization of anger-related behaviors. When inspecting 


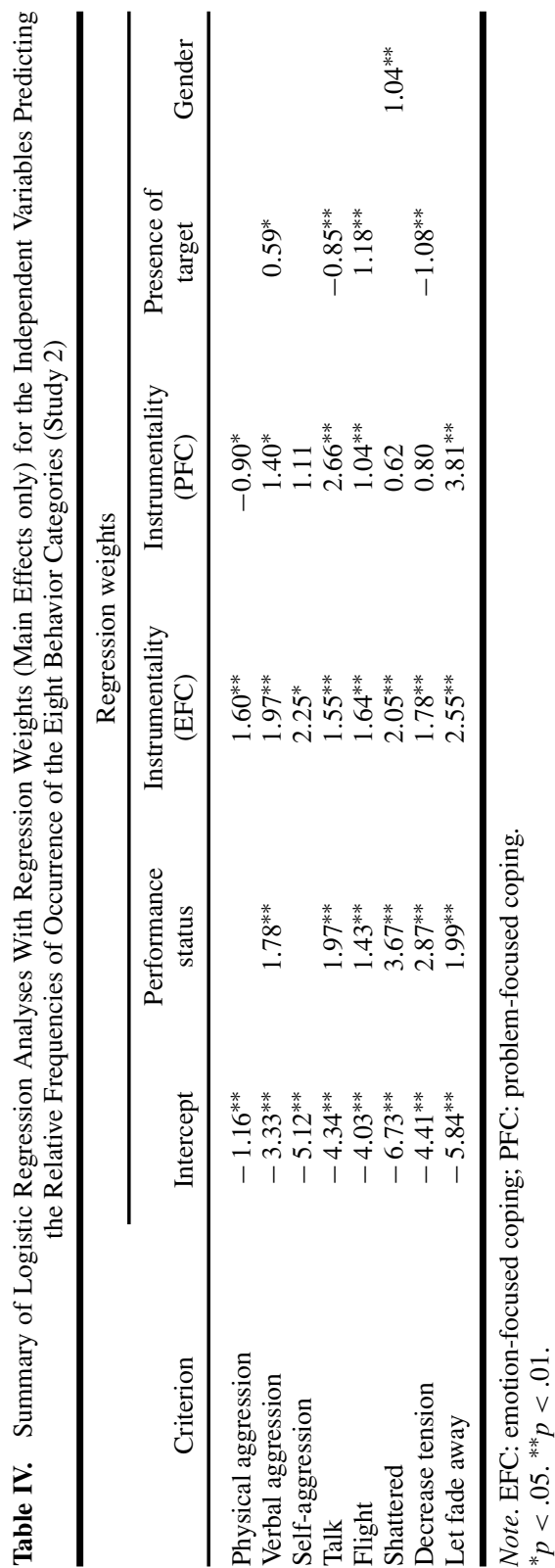


overall behavior frequencies, we again see a prominent fight-flight pattern, which confirms that an anger-provoking situation bears similarity to a stressful event. Furthermore, the use of a balanced sample with regard to gender did not clearly alter the behavior frequencies, suggesting that the findings from Study 1 were not sample-driven. In fact, gender differences were only found for the shattered category, which was more frequently reported by women (for a similar result, see also, e.g., Timmers et al., 1998).

Furthermore, the results of Study 2 showed that all behavior categories, apart from physical aggression, were more frequently executed than inhibited. Otherwise, the level of inhibition was very high for physical aggression.

The results of Study 2 also showed that most behavior categories occur both with and without a coping intention. Furthermore, in general, proportions of occurrence in the no coping condition were somewhat lower than those in the coping conditions, suggesting that anger-related behaviors rather often stem from a coping intention.

If we examine behaviors in the two coping conditions, for six behavior categories, coping primarily pertained to coping with the emotion. Moreover, this pattern was more pronounced for fight-flight behaviors. With regard to the flight category, this finding is rather tautological: People are not likely to cope with the situation if they ignore the person at whom they are angry. With regard to the fight behaviors, the predominance of emotion-focused coping is consistent with previous findings that people may engage in aggressive behavior because they hope and expect that doing so will enable them to feel better (e.g., Bushman, Baumeister, \& Philips, 2001).

Talk and let fade away were found to be used more often for problemfocused coping. Both categories have a closely related or "twin-category". The "twin-category" for talk is "verbal aggression", both categories implying the use of words; the difference between the two is that "talk" does not imply other-harm, which may be considered a prerequisite for effective problem-focused coping. Furthermore, the "twin-category" for let fade away is "decrease tension". Both categories share a reduction of arousal, but they differ with respect to how this is achieved: Whereas "decrease tension" consists of more active behaviors through which one may avoid thinking about the problem, "let fade away" contains more passive behaviors that imply a direct connection with the problem (which may facilitate problem-focused coping).

The results of Study 2 demonstrate that the mere presence of the target may influence the display of anger-related action tendencies and behaviors, verbal aggression and flight being more frequently reported if the target is present. Both findings are fairly logical: the verbal aggression category contains behaviors that are specifically directed at the target, and can only be executed if the target is present. Concerning flight, there is no reason to flight if the target is absent. On the other hand, talk and decrease tension were reported less frequently when the target was present. Regarding talk, this result can be understood if this category 
is dominated by talking with others (i.e., social sharing), for which the target preferably has to be absent. Regarding decrease tension, the presence of the source of the tension may prohibit tension reduction.

\section{CONCLUDING REMARKS}

In this paper, a systematic approach has been adopted to construct and crossvalidate a taxonomy of anger-related behaviors. The results of our studies suggest that our attempt has been successful in that we arrived at a taxonomy that is fairly comprehensive and that allows for a reliable categorization. Inspection of the taxonomy further indicates that aggression occupies a central place in it; moreover, it especially dominates the picture when the anger becomes more intense.

However, the set of anger-related behaviors is much broader than aggression. First, aggression is part of a broader fight-flight pattern. Furthermore, several other behavior categories occurred, most of which explicitly or implicitly refer to a tension that accompanies anger. It is clear that using this taxonomy in further studies may have many advantages. One may, for instance, think of examining individual differences and additional situational variables, which so far, have mainly been investigated in the context of aggression alone.

As is invariably the case, our studies are limited by the sample (Dutchspeaking Belgian university students). As such, our results primarily apply to young adults. Moreover, although there is no reason to think that our participants react differently when angry than participants from other European or North American countries, there may be reasons to suspect differences with other, more distant cultures (see e.g., Kassinove et al., 1997). Our studies are also limited on the level of the method. First, we relied on self-report. Second, recalled angerinstances may be biased toward more dramatic, emotion-loaded situations. Third, the fact that participants were asked to summarize across their past experiences of anger may have caused them to report not only anger-related behaviors, but also their naïve theories about this relationship. Note, however, that a more specific situational context (see Study 2) did not affect the overall frequency pattern. In general, a replication using other samples and methods could add to the validity and generalizability of our findings.

Despite these limitations, the results of the presented studies yield a rich and meaningful picture that replicates, reconciles, and meaningfully extends previous research findings about anger. As such, we hope to have contributed to a better understanding of anger-related behaviors and their determinants.

\section{ACKNOWLEDGMENTS}

The research reported in this paper was supported by Grant GOA/00/02 from the Research Fund of the University of Leuven. We thank John Nezlek for his comments on a previous version of this paper. 


\section{REFERENCES}

Averill, J. R. (1982). Anger and aggression: An essay on emotion. New York: Springer-Verlag.

Berkowitz, L. (1990). On the formation and regulation of anger and aggression: A cognitiveneoassociationistic analysis. American Psychologist, 45, 494-503.

Bushman, B. J., Baumeister, R. F., \& Philips, C. M. (2001). Do people aggress to improve their mood? Catharsis beliefs, affect regulation opportunity, and aggressive responding. Journal of Personality and Social Psychology, 81, 17-32.

Cannon, W. B. (Ed.). (1932). The wisdom of the body. New York: Norton.

Cohen, J. (1960). A coefficient of agreement for nominal scales. Educational and Psychological Measurement, 20, 37-46.

Coxon, A. P. M. (1999). Sorting data: Collection and data analysis. London: Sage.

Deffenbacher, J. L., Lynch, R. S., Oetting, E. R., \& Yingling, D. A. (2001). Driving anger: Correlates and a test of state-trait theory. Personality and Individual Differences, 31, 1321-1331.

Diener, E. (1976). Effects of prior destructive behavior, anonymity, and group presence on deindividuation and aggression. Journal of Personality and Social Psychology, 33, 497-507.

Fitness, J., \& Fletcher, J. O. (1993). Love, hate, anger, and jealousy in close relationships: A prototype and cognitive appraisal analysis. Journal of Personality and Social Psychology, 65, 942-958.

Folkman, S. (1984). Personal control and stress and coping processes: A theoretical analysis. Journal of Personality and Social Psychology, 46, 839-852.

Frijda, N. H., Kuipers, P., \& Ster chure, E. (1989). Relations among emotion, appraisal, and emotional action readiness. Journal of Personality and Social Psychology, 57, 212-228.

Herrald, M. M., \& Tomaka, J. (2002). Patterns of emotion-specific appraisal, coping, and cardiovascular reactivity during an ongoing emotional episode. Journal of Personality and Social Psychology, $83,434-450$.

Kassinove, H., Sukhodolsky, D. G., Tsytsarev, S. V., \& Solovyova, S. (1997). Self-reported anger episodes in Russia and America. Journal of Social Behavior and Personality, 12, 301-324.

Krueger, R. F. (1999). The structure of common mental disorders. Archives of General Psychiatry, 56, 921-926.

Linden, W., Hogan, B. E., Rutledge, T., Chawla, A., Lenz, J. W., \& Leung, D. (2003). There is more to anger coping than "in" or "out." Emotion, 3, 12-29.

Milligan, G. W., \& Cooper, M. C. (1985). An examination of procedures for determining the number of clusters in a data set. Psychometrika, 50, 159-179.

Pennebaker, J. W., Zech, E., \& Rimé, B. (2001). Disclosing and sharing emotion: Psychological, social and health consequences. In M. S. Stroebe, R. O. Hansson, W. Stroebe, \& H. Schut (Eds.), Handbook of bereavement research: Consequences, coping, and care (pp. 517-539). Washington, DC: American Psychological Association.

Rotter, J. B. (1971). External control and internal control. Psychology Today, 5, 37-42, 58-59.

Sonnemans, J., \& Frijda, N. H. (1994). The structure of subjective emotional intensity. Cognition and Emotion, 8, 329-350.

Spielberger, C. D., Krasner, S. S., \& Solomon, E. P. (1988). The experience, expression and control of anger. In M. P. Janisse (Ed.), Health psychology: Individual differences and stress (pp. 89-108). New York: Springer-Verlag.

Suter, J. M., Byrne, M. K., Byrne, S., Howells, K., \& Day, A. (2002). Anger in prisoners: Women are different from men. Personality and Individual Differences, 32, 1087-1100.

Timmers, M., Fischer, A. H., \& Manstead, A. S. R. (1998). Gender differences in motives for regulating emotions. Personality and Social Psychology Bulletin, 24, 974-985. 